\title{
Androgen signaling pathways driving reproductive and metabolic phenotypes in a PCOS mouse model
}

\author{
Ali Aflatounian1, Melissa C Edwards1,2, Valentina Rodriguez Paris', Michael J Bertoldo1,3, Reena Desai², \\ Robert B Gilchrist ${ }^{1}$, William L Ledger1, David J Handelsman² and Kirsty A Walters ${ }^{1,2}$
}

'Fertility and Research Centre, School of Women's \& Children's Health, University of New South Wales Sydney, New South Wales, Australia 2Andrology Laboratory, ANZAC Research Institute, University of Sydney, Concord Hospital, Sydney, New South Wales, Australia

${ }^{3}$ Laboratory for Ageing Research, School of Medical Sciences, University of New South Wales Sydney, New South Wales, Australia

Correspondence should be addressed to K A Walters: k.walters@unsw.edu.au

\begin{abstract}
As the mechanistic basis of polycystic ovary syndrome (PCOS) remains unknown, current management relies on symptomatic treatment. Hyperandrogenism is a major PCOS characteristic and evidence supports it playing a key role in PCOS pathogenesis. Classically, androgens can act directly through the androgen receptor (AR) or, indirectly, following aromatization, via the estrogen receptor (ER). We investigated the mechanism of androgenic actions driving PCOS by comparing the capacity of non-aromatizable dihydrotestosterone (DHT) and aromatizable testosterone to induce PCOS traits in WT and $A r$-knockout (ARKO) mice. DHT and testosterone induced the reproductive PCOS-like features of acyclicity and anovulation in WT females. In ARKO mice, DHT did not cause reproductive dysfunction; however, testosterone treatment induced irregular cycles and ovulatory disruption. These findings indicate that direct AR actions and indirect, likely $E R$, actions of androgens are important mediators of PCOS reproductive traits. DHT, but not testosterone, induced an increase in body weight, body fat, serum cholesterol and adipocyte hypertrophy in WT mice, but neither androgen induced these metabolic features in ARKO mice. These data infer that direct AR-driven mechanisms are key in driving the development of PCOS metabolic traits. Overall, these findings demonstrate that differing PCOS traits can be mediated via different steroid signaling pathways and indicate that a phenotype-based treatment approach would ensure effective targeting of the underlying mechanisms.
\end{abstract}
Key Words
- polycystic ovary syndrome
- hyperandrogenism
- androgen receptor
- estrogen receptor

\section{Introduction}

Polycystic ovary syndrome (PCOS) is a significant health problem. It is estimated to have a global prevalence of $\sim 6-20 \%$, depending on the diagnostic criteria used, making it the most common endocrine disorder among women of reproductive age (March et al. 2010, Dumesic et al. 2015). Unfortunately, as the pathogenesis of PCOS remains unclear, there is no cure, and in the absence of mechanistic understanding, current medical management relies suboptimally on ad hoc empirical treatment of symptoms. PCOS is a complex and heterogeneous condition impacting a wide range of organs reflected in the broad range of clinical manifestations, including endocrine, reproductive, metabolic and psychological disorders (Dumesic etal. 2015). Endocrine and reproductive 
features include hyperandrogenism, luteinising hormone (LH) hypersecretion, sub-fertility, ovulatory dysfunction, aberrant follicular maturation and an increased risk of miscarriage (Dumesic et al. 2015). PCOS is also associated with a significant metabolic impact, as PCOS women often display obesity, metabolic syndrome, hyperinsulinemia, insulin resistance, hepatic steatosis and dyslipidemia, and these traits heighten the risk of type 2 diabetes and cardiovascular disease (Shorakae et al. 2014, Dumesic et al. 2015, Rubin et al. 2017, Glintborg et al. 2018).

While there have been several diagnostic criteria for PCOS, including the Rotterdam (Rotterdam Workshop Group 2004), Androgen Excess and PCOS (AE-PCOS) Society (Azziz et al. 2006) and the National Institutes of Health (NIH) criteria (Zawadzki \& Dunaif 1992), the international evidence-based PCOS guidelines favor the Rotterdam diagnostic criteria (Teede et al. 2018). For a diagnosis, there is a requirement for two of the following three PCOS features: clinical and/or biochemical androgen excess, oligo- or anovulation and polycystic ovarian morphology on ultrasound, after exclusion of related disorders (Rotterdam Workshop Group 2004, Teede et al. 2018). Hyperandrogenism is the most common and consistent endocrine alteration in PCOS patients (Azziz et al. 2006, Livadas et al. 2014) and numerous studies have provided strong evidence that androgens and their actions through the androgen receptor (AR) are key mediators in the development of PCOS (Walters et al. 2019). Androgen production is up to 20 times greater from theca cells derived from PCOS patients (Gilling-Smith et al. 1994), and clinical exposure to endogenous (congenital adrenal hyperplasia (Lucis et al. 1966)) or exogenous (female to male transgenders (Pache \& Fauser 1993)) androgens can induce the formation of polycystic ovary morphology. Similarly, increased androgen exposure of rodents, sheep and rhesus monkeys, both during prenatal and early postnatal life, induces a wide range of PCOS characteristics (Walters et al. 2018a). The AR has been highlighted a key mediator, as treatment of PCOS patients (Paradisi et al. 2013) and a PCOS animal model (Ryan et al. 2018) with the AR antagonist flutamide restored cycle irregularity and ovulation. Moreover, recent animal studies using long-term blockade of AR signaling (Silva et al. 2018) and transgenic mouse models that silence the action of androgens (Caldwell et al. 2015) have established that androgen-driven actions, in particular AR-mediated neuroendocrine mechanisms (Caldwell et al. 2017), are key mediators in the development of experimental PCOS.

While there is strong evidence that AR-mediated actions play an important role in the evolution of PCOS
(Walters 2015, Walters et al. 2018b), testosterone can be aromatized into E2, the corresponding estrogens (Hillier et al. 1994, Ghayee \& Auchus 2007), and act via the estrogen receptor (ER). Notably, testosterone, which is readily aromatized into estradiol, is a major circulating androgen in women and is elevated in the majority of women with PCOS (Davison \& Davis 2003, Handelsman et al. 2017). This raises the hypothesis that some androgen actions involved in the development of PCOS traits could potentially be indirect and mediated via the estrogenic pathways. In support of this, exposure to elevated levels of estrogens (estradiol valerate) induces anovulation and polycystic ovaries in rats, which resemble reproductive features observed in PCOS patients (McCarthy \& Brawer 1990, Stener-Victorin et al. 2000). Data from the sheep PCOS model suggests that the programming of adult disease could occur via both androgenic and estrogenic pathways. Prenatal treatment with testosterone increases not only the maternal but also the fetal concentrations of androgens and estradiol (Veiga-Lopez et al. 2011, Abi Salloum et al. 2015), and treatment with testosterone, but not DHT, induces the PCOS characteristics of polycystic ovaries and abnormal antral follicle morphology (Smith et al. 2009). Furthermore, as clomiphene citrate (an ER modulator) and letrozole (an inhibitor of estradiol synthesis) are first-line pharmacological treatment options to restore ovulation in PCOS patients (Legro 2016, Teede et al. 2018, Wang et al. 2019), this infers a potential role for ER-mediated actions in the signaling pathways underlying the development of PCOS. Therefore, the objective of the present study was to investigate the underlying steroid signaling pathways involved in the development of experimental PCOS by comparing the capacity of nonaromatizable DHT vs aromatizable testosterone to induce PCOS traits in WT mice (functional AR and ER) and androgen receptor knockout mice (non-functional AR but functional ER) (Fig. 1).

\section{Materials and methods}

\section{Animals}

Mice were maintained under standard housing conditions (ad libitum access to food and water in a temperatureand humidity-controlled, $12 \mathrm{~h}$ light: $12 \mathrm{~h}$ darkness cycle environment) at the ANZAC Research Institute. All protocols were approved by the Sydney Local Health District Animal Welfare Committee within National Health and Medical Research Council guidelines for animal experimentation. Mice were housed together 


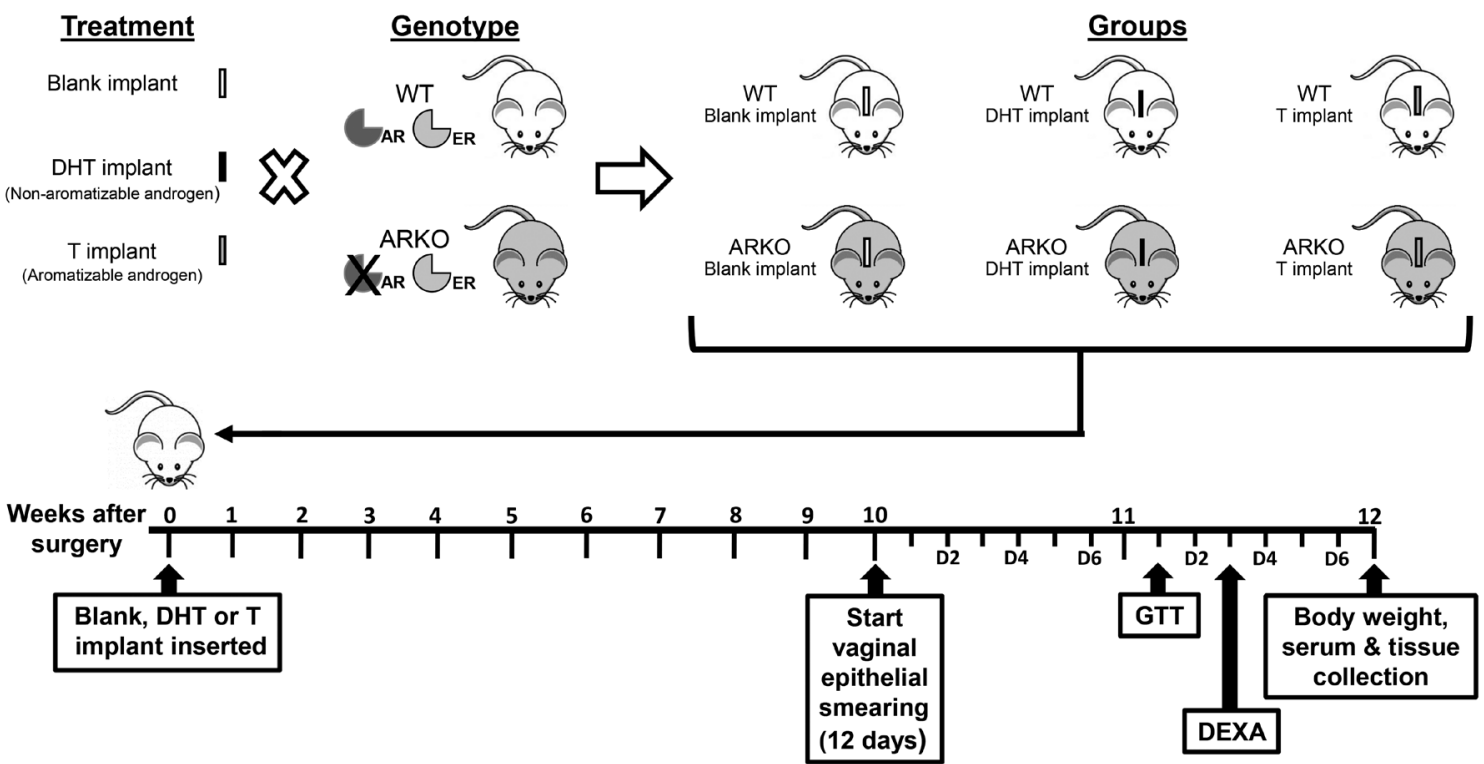

\section{Figure 1}

Experimental design. For this study, PCOS was induced in WT and global androgen receptor knockout (ARKO) female mice by s.c. insertion of dihydrotestosterone (DHT) or testosterone (T) implants in peripubertal mice for 3 months. Control mice were implanted with a blank (empty) pellet. Estrous cycling, glucose tolerance test (GTT), body composition (DEXA-scan) and body weights were assessed before collection of serum and tissues 12 weeks after administration of treatments.

based on treatment groups. Female homozygous ARKO mice were generated on a $\mathrm{C} 57 \mathrm{Bl} / 6 \mathrm{~J}$ background by crossing ARflox mice with Sox2-Cre mice, as previously described (Caldwell et al. 2017). Genomic DNA isolated from toe clip or tail biopsy was used as a template for PCR genotyping to detect rearrangements in the mouse $\mathrm{Ar}$ gene as previously described (Caldwell et al. 2017).

\section{Experimental design and induction of PCOS traits in a PCOS mouse model}

We examined the ability of the androgens DHT (nonaromatizable) and testosterone (aromatizable) to induce PCOS-like characteristics in WT (control) and global androgen receptor knockout (ARKO, complete global loss of AR signaling (Walters et al. 2007)) mice (Fig. 1). Based on our previous development of a PCOS mouse model (Caldwell et al. 2014), peripubertal (4-5 weekold) female mice were implanted s.c. with either a DHT or testosterone 1-cm Silastic implant (i.d., $1.47 \mathrm{~mm}$; o.d., 1.95 mm; Dow Corning; 508-006) containing about $10 \mathrm{mg}$ DHT or testosterone or empty (control). Silastic implants are made in-house and provide steady-state DHT release for at least 6 months (Singh et al. 1995). At the time of animal collection, all implants were removed and checked to ensure they still had DHT or testosterone powder in them (which they did) and had not ruptured or leaked. Groups were identified as WT Control $(n=8)$, WT+DHT $(n=8)$, WT+testosterone $(n=6)$, ARKO Control $(n=9)$, ARKO+DHT $(n=9)$ and ARKO+testosterone $(n=7)$. Pre-collection assessments of estrous cycle assessments, glucose tolerance tests (GTTs) and Dual energy $\mathrm{x}$-ray absorptiometry analyzer (DEXA) scans were performed at 10-11 weeks after the initiation exposure to androgens (Fig. 1). DEXA was performed under isoflurane inhalation anesthesia 1-2\%, while all terminal collections were carried out under ketamine/xylazine anesthesia. Mice were killed and tissues collected 12 weeks after implants were inserted.

\section{Assessment of estrous cycle}

Ten weeks after implant insertion, estrous cycling was assessed for a 12-day period. Estrous cycle stage was determined daily by light microscope analysis of vaginal epithelial cell smears, as previously described (Caldwell et al. 2014). Briefly, smears were collected using $15 \mu \mathrm{L}$ of $0.9 \%$ sterile saline, transferred to glass slides to air dry and stained with $0.5 \%$ toluidine blue before examination under a light microscope. The stage of the estrous cycle was determined based on the presence or absence of leukocytes, cornified epithelial and nucleated epithelial cells. 
Ovary preparation, morphological analysis and follicle health

Dissected ovaries were weighed, fixed in $4 \%$ paraformaldehyde at $4^{\circ} \mathrm{C}$ overnight and stored in $70 \%$ ethanol before histological processing. Ovaries were processed through graded alcohols, embedded into glycol methacrylate resin (Technovit 7100; Heraeus Kulzer), serially sectioned at $20 \mu \mathrm{m}$, stained with periodic acidSchiff and counterstained with hematoxylin. To avoid bias, all ovaries were analyzed without prior knowledge of genotype/treatment group. As previously described (Caldwell et al. 2014), total number of corpora lutea (CL) (identified by morphological properties consistent with luteinized follicles and visible throughout several serial sections) were quantified on all serial sections throughout each ovary using an Olympus BX60 light microscope and ImageJ version 1.48 software (opensource, developed by the National Institutes of Health). Large antral follicles were assessed on all ovarian sections and were classified as containing a single large antrum. To avoid assessment repetition, follicles were only assessed in the section where the oocyte's nucleolus was visible. Large antral follicles were categorized unhealthy if they possessed a degenerate oocyte and/or more than $10 \%$ of the granulosa cells were pyknotic in appearance, and the percentage of unhealthy follicles per ovary was calculated. All large antral follicles were assessed for granulosa celllayer thickness using ImageJ version 1.48 software (NIH), as previously described (Caldwell et al. 2014).

\section{Steroid analysis}

Blood was collected from females by cardiac exsanguination under ketamine/xylazine anesthesia, and serum was stored at $-20^{\circ} \mathrm{C}$. Serum levels of DHT, testosterone and androstenedione (A4) (extracts of $100 \mu \mathrm{L}$ of mouse serum) and intra-ovarian estradiol (E2) and estrone (E1) were measured in by LC-MS/MS, as previously described (McNamara et al. 2010, Desai et al. 2019). The limits of quantitation (defined as the lowest level that can be detected with a CV of $<20 \%$ ) were $100 \mathrm{pg} / \mathrm{mL}$ for DHT, $25 \mathrm{pg} / \mathrm{mL}$ for testosterone and $50 \mathrm{pg} / \mathrm{mL}$ for A4 in serum samples and $5 \mathrm{pg} / \mathrm{mL}$ for $\mathrm{E} 2$ and $3 \mathrm{pg} / \mathrm{mL}$ for $\mathrm{E} 1$ in ovarian tissue samples.

\section{Body composition}

Body composition measurements were performed on a Lunar PIXImus Densitometer for mice (GE Medical Systems).

(C) 2020 Society for Endocrinology Published by Bioscientifica Ltd. Printed in Great Britain

\section{Fat-pad weight and adipocyte morphometric analysis}

Brown, retroperitoneal, mesenteric and parametrial fat pads were weighed at collection. Parametrial fat pads were fixed in $4 \%$ paraformaldehyde, embedded in paraffin, sectioned at $8 \mu \mathrm{m}$ and then stained with hematoxylin and eosin. Parametrial adipocyte size was quantified by histomorphometry in images taken at $\times 40$ magnification under a light Olympus BX60 microscope with Stereo Investigator software (DP70 and ImageJ). Five distinct images were taken from each of three sections of the fat pad, with at least $200 \mu \mathrm{m}$ separating these sections, as described (Caldwell et al. 2014).

\section{Adiponectin assay}

Total full-length mouse adiponectin concentrations were measured in serum using a Quantikine ELISA Kit from R\&D Systems (MRP300) according to manufacturer's instructions. The mean minimum detectable dose of mouse adiponectin was $0.003 \mathrm{ng} / \mathrm{mL}$.

\section{Glucose tolerance test}

Glucose tolerance tests were performed by blood glucose measurement after an i.p. glucose injection, as previously reported (Caldwell et al. 2014). Mice were fasted for $6 \mathrm{~h}$ before a baseline blood glucose reading, followed by an i.p. injection of glucose at $2 \mathrm{~g} / \mathrm{kg}$ body weight (BW). Blood glucose was then measured at 15-, 30-, 60- and 90-min periods after glucose injection. Blood was obtained from a tail prick, and blood glucose was measured with glucose strips and an Accu-Chek glucometer (Roche).

\section{Cholesterol and triglyceride assays}

Serum levels of total cholesterol and triglycerides were assayed enzymatically with commercial kits obtained from Wako (Cholesterol E kit, catalog no. 439-17501; and Triglyceride E kit, catalog no. 342-40201).

\section{Statistics}

Statistical analysis was performed using GraphPad Prism 8. Statistical differences were tested by two-way ANOVA (to assess the effect of genotype, treatment and genotype $\mathrm{X}$ treatment interaction) with post hoc test using Fisher's least significant difference multiple-comparison test. Proportions (\% of ovaries with CL) were analyzed by Fisher's exact test. For statistical analysis of steroid levels, 
where a significant proportion of serum sex steroids samples were below the limits of detection (testosterone, DHT), a Fisher's exact test was used to compare the proportions of detectable vs nondetectable samples within genotype, as previously described (Cheng et al. 2013). GTT was analyzed by a repeated-measures two-way ANOVA. $P \leq 0.05$ was considered statistically significant.

\section{Results}

\section{Both DHT and testosterone induce acyclicity in WT mice, but only testosterone causes estrous cycle dysfunction in ARKO mice}

To determine the mode of action of androgen excess in the hyperandrogenic PCOS-like mouse model, estrous cycle patterns were assessed for 12 consecutive days, 10 weeks after the insertion of an implant. Acyclicity was evident in $100 \%$ of WT females treated with DHT $(8 / 8)$ or testosterone (6/6) (Fig. 2A, $P<0.01$; Fig. 2B). In contrast to WT control females that cycled regularly through the four different stages of the estrous cycle, DHT- and testosteronetreated WT females spent most time at the diestrus stage (Fig. 2C; $P<0.01)$. ARKO females treated with a blank or DHT implant maintained normal estrous-cycle patterns
(Fig. 2A, B and C). However, testosterone-treated ARKO females completed significantly fewer cycles (Fig. 2A, $P<0.01$ ), exhibited irregular cycles (Fig. 2B) and spent the majority of time at the metestrus stage of the estrous cycle (Fig. 2C, $P<0.01$ ). As the AR is non-functional in ARKO mice and testosterone can be aromatized to estradiol, these findings infer that the development of irregular cycles observed in the ARKO+testosterone group may have been mediated via ER-driven mechanisms.

\section{Predictions of androgenic and estrogenic activity}

Analysis of serum steroid levels by liquid chromatographytandem mass spectrometry (LC-MS/MS) revealed that DHT and testosterone were undetectable in the majority of samples apart from WT and ARKO females implanted with a DHT (Fig. 3A; $P<0.01$ ) or a testosterone (Fig. 3B; $P<0.01)$ implant, respectively. Additionally, analysis of circulating A4 levels identified no change in levels in WT or ARKO females (Fig. 3C). In order to predict the presence of androgenic and estrogenic activity present in each treatment group, tissues that act as in vivo bioassays for androgenic and estrogenic activity were assessed. Mouse kidneys are highly responsive to androgens and increase in size in response to androgen treatment (Shukla et al. 1992),
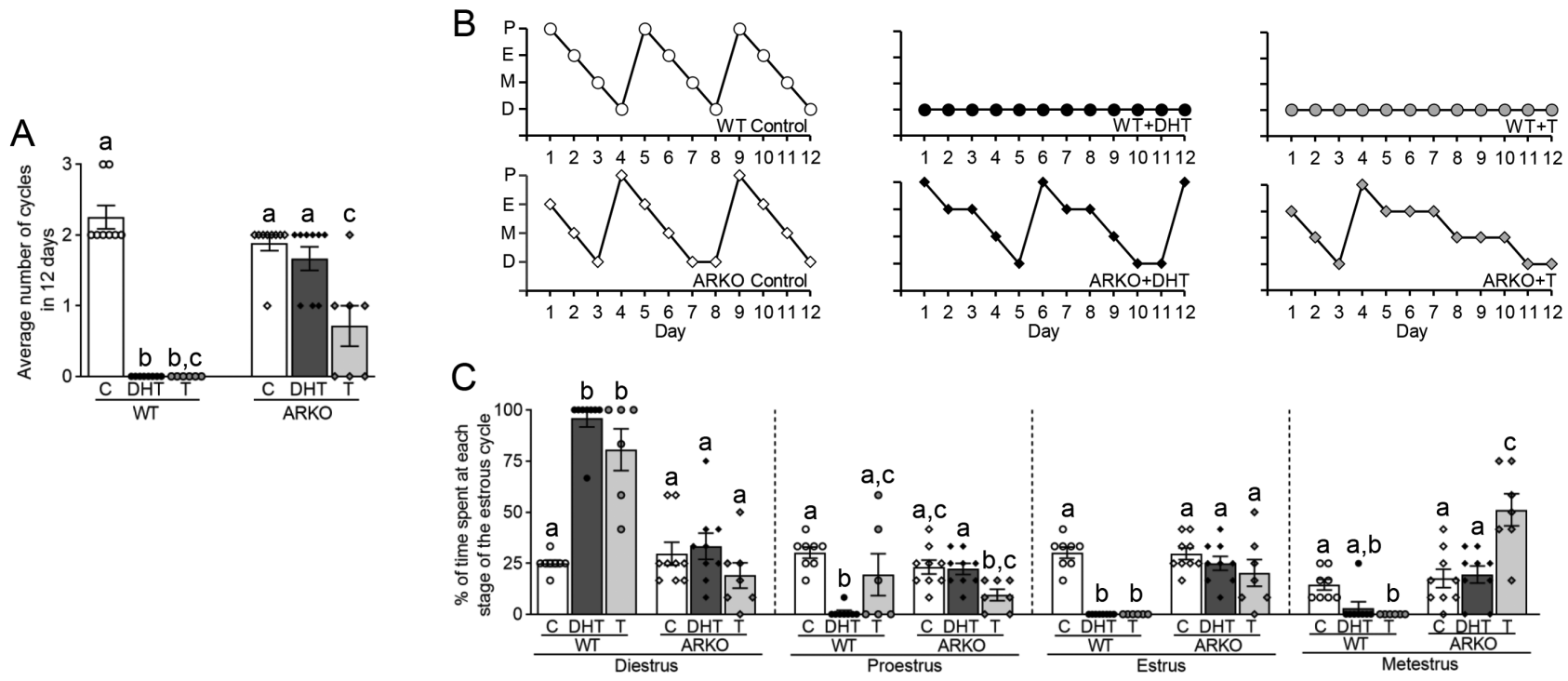

\section{Figure 2}

Both DHT and testosterone (T) induce acyclicity in WT mice, but only testosterone causes estrous cycle dysfunction in ARKO mice. (A) Average number of completed estrous cycles within a 12-day period, showing development of acyclicity in DHT- and testosterone-induced PCOS WT mice and significantly reduced cycles in testosterone-induced PCOS ARKO female mice. $n=6-9$ per treatment/genotype group. (B) Representative estrous-cycle patterns in female mice over 12 consecutive days assessed 10-12 weeks post implant, showing DHT- and testosterone-induced acyclicity in WT mice, testosteroneinduced estrous cycle irregularity in ARKO females, but ARKO mice were protected from DHT-induced acyclicity. P, proestrus; E, estrus; M, metestrus; D, diestrus. (C) Proportion of time spent at each stage of the estrous cycle, showing significantly altered estrous cycles in DHT and testosterone exposed WT mice, and testosterone exposed ARKO mice. For histogram graphs, data are the mean \pm s.E.M.; different letters denote significant statistical differences; two-way ANOVA followed by Fishers's LSD post-hoc test. 
A

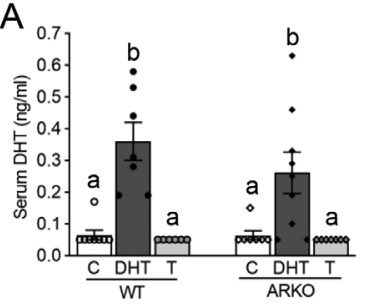

D

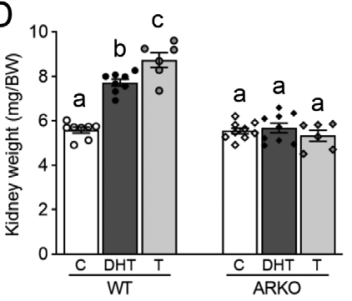

B
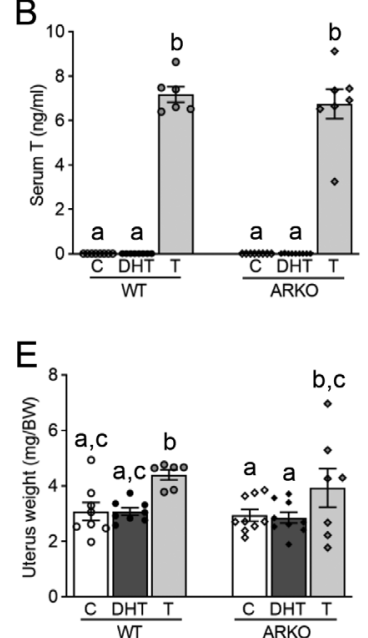

C

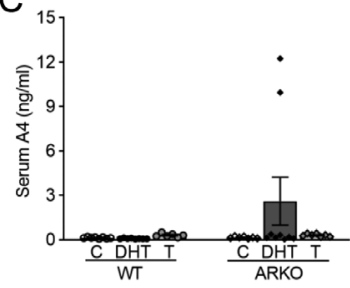

$\mathrm{F}$

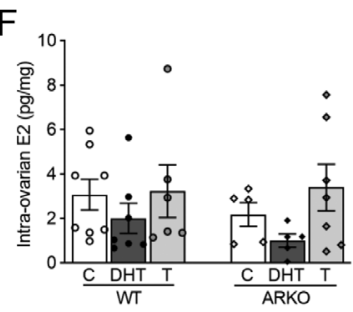

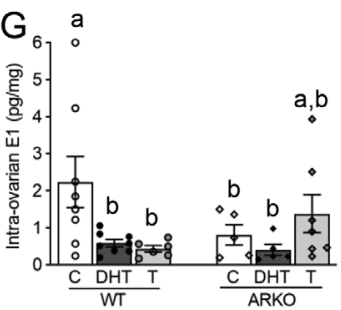

\section{Figure 3}

Indicators of androgenic and estrogenic activity. (A) Serum DHT concentration: only DHT-treated WT and ARKO mice displayed increased levels of DHT in their sera. (B) Serum testosterone (T) concentration: only testosterone-treated WT and ARKO mice exhibited increased levels of testosterone in their sera. (C) Serum A4 concentration: no change observed between any groups. (D) Kidney weights: confirming an AR-mediated increase in kidney weight only in DHT and testosterone-treated WT female mice and not ARKO female mice. (E) Uterus weight: confirming an increase in uterus weight only in testosterone-treated WT and ARKO female mice, likely via ER-mediated mechanisms. $n=6-9$ per treatment/genotype group. (F) Intra-ovarian estradiol (E2) concentrations: revealing a trend to higher levels of E2 in testosterone-treated ARKO mice. (G) Intra-ovarian estrone (E1) concentrations: revealing a trend to higher levels of E1 in testosterone-treated ARKO mice. $n=5-8$ per treatment/genotype group. For all graphs, data are the mean \pm S.E.M.; different letters denote significant statistical differences; Fisher's exact test (A and B) and two-wayANOVA followed by Fishers's LSD post-hoc test (C, D, E, F and G).

while estrogens stimulate growth of the uterus (Armstrong et al. 1976). Both DHT and testosterone significantly increased kidney weights in WT mice (Fig. 3D; $P<0.01$ ), but no change was observed in the kidney weight of ARKO mice treated with DHT or testosterone (Fig. 3D). Uterine weight significantly increased in both WT (Fig. 3E; $P<0.01$ ) and ARKO (Fig. 3E; $P<0.05$ ) females in response to testosterone treatment. In addition, as serum E2 levels were undetectable by this method (McNamara et al. 2010), we measured intra-ovarian estradiol (E2) and estrone (E1) levels, and ARKO mice treated with testosterone displayed a non-significant trend of elevated intra-ovarian E2 and E1 concentrations (Fig. 3F and G).

\section{Both DHT and testosterone induce anovulation and ovarian characteristics of PCOS in WT mice, but only testosterone causes ovulatory dysfunction in ARKO mice}

Oligo/anovulation is a defining reproductive trait of PCOS, and the development of this PCOS-like trait was confirmed by the detection of anovulation in all WT females treated with DHT or testosterone. Histologically, corpora lutea (CL) were absent in all DHT and testosterone-treated WT females (Fig. 4A, B and D; $P<0.01$ ). In addition, the absence of $\mathrm{CL}$ led to a significant reduction in ovarian weight in both the WT+DHT and WT+testosterone groups (Fig. 4C; $P<0.01$ ). Consistent with previous findings (Caldwell et al. 2017), a global loss of AR signaling protected against the DHT-induced ovulatory dysfunction (Fig. 4A, B and D) and associated reduction in ovarian weight (Fig. 4C). However, in line with our finding that testosterone treatment caused irregular estrous cycles in the absence of AR signaling (Fig. 2A, B and C), treatment of ARKO females with testosterone induced the development of ovulatory dysfunction, evident by a significant reduction in the number of CL present in their ovaries (Fig. 4A, $P<0.05$; Fig. $4 \mathrm{~B}, P<0.01)$ and a significant decrease in ovarian weight (Fig. 4C; $P \leq 0.05$ ).

As expected and previously reported (Caldwell et al. 2014), peripubertal DHT treatment induced a characteristic polycystic appearance in WT ovaries (Fig. 5A). Similarly, compared to WT controls, exposure of WT ovaries to testosterone also caused a similar histological appearance of polycystic ovaries (Fig. 5A). Control and DHT-treated ARKO females did not display this phenotype. However, ovaries collected from testosterone-treated ARKO females did resemble the characteristic polycystic appearance (Fig. 5A). In addition, compared with controls, the ovaries of DHT- or testosterone-treated WT females displayed a significant increase in the presence of morphologically unhealthy large antral follicles (Fig. 5B; $P<0.05$ ), 

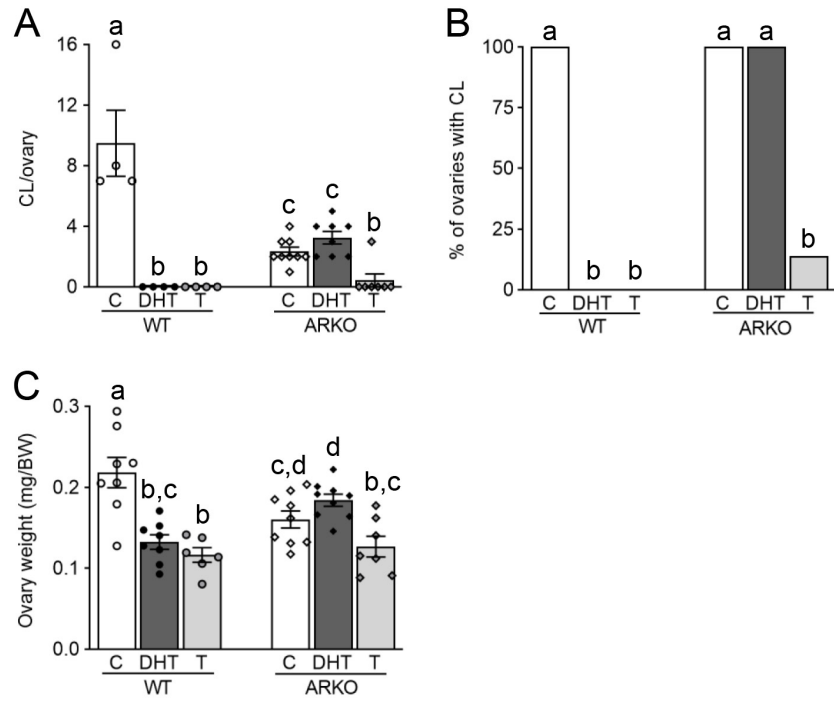

D

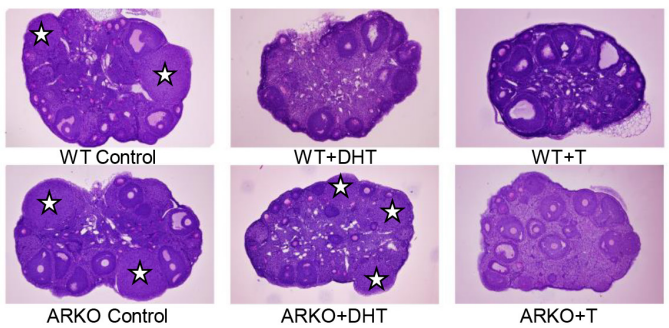

Figure 4

Both DHT and testosterone (T) induce anovulation and ovarian characteristics of PCOS in WT mice, but only testosterone causes ovulatory dysfunction in ARKO mice. (A) Average number of corpora lutea (CL) per ovary: showing development of anovulation in DHT- and testosterone-induced PCOS WT mice and significantly reduced CL numbers per ovary in testosterone-induced PCOS ARKO female mice. $n=4-9$ per treatment/genotype group. (B) Proportion of ovaries exhibiting $\mathrm{CL}$ : showing a complete loss of $\mathrm{CL}$ in DHT and testosterone-treated WT ovaries and significantly fewer testosterone-treated ARKO ovaries exhibiting CL. (C) Ovary weights: confirming DHT- and testosteroneinduced reduction in ovarian weight in PCOS WT mice and testosteroneinduced PCOS ARKO female mice. $n=6-9$ per treatment/genotype group. (D) Histological cross-sections of representative ovaries from each treatment group: showing the presence of $\mathrm{CL}$ in WT Control, ARKO Control and ARKO+DHT ovaries only. Star: corpora lutea; magnification: $4 \times$. For all graphs, data are the mean \pm S.E.M.; different letters denote significant statistical differences; two-way ANOVA followed by Fishers's LSD post-hoc test ( $A$ and $C$ ) and Fisher's exact test (B).

as large antral follicles exhibited an increase in pyknotic granulosa cells (Fig. 5C). Furthermore, granulosa celllayer thickness was decreased in testosterone-treated WT females (Fig. 5D; $P<0.01$ ) and there was a tendency in WT females (Fig. 5D; $P=0.07$ ) in response to DHT treatment. Conversely, these features were completely prevented in the androgen exposed ARKO females, as the proportion of unhealthy large antral follicles (Fig. 5B and C) and granulosa cell-layer thickness (Fig. 5D) did not differ from controls.
DHT, but not testosterone, increased body weight and adiposity in WT mice, and neither androgen impacted body composition in ARKO mice

There is a strong association between PCOS and obesity, with obesity worsening hyperandrogenism in PCOS (Lim et al. 2012). We therefore investigated the mechanism of androgen excess in mediating weight gain in the hyperandrogenic PCOS-like mouse model. In WT females, DHT, but not testosterone, treatment induced a significant increase in body weight (Fig. 6A; $P<0.01$ ), body fat (Fig. 6B) and retroperitoneal (Fig. 6C; $P<0.01$ ), mesenteric (Fig. 6C; $P<0.01$ ) and parametrial fat depot weights (Fig. 6C; $P<0.01)$. Brown fat depot weight was significantly increase in WT mice exposed to DHT and testosterone (Fig. 6C; $P<0.05$ ). In contrast to WT females, in ARKO mice, neither DHT nor testosterone induced significant increases in body weight or fat depot weights (Fig. 6A, B and C).

In WT mice DHT, but not testosterone, induced the development of adipocyte hypertrophy and reduced adiponectin levels, and neither androgen impacted adipocyte morphology or adiponectin levels in ARKO mice

We discovered that, while WT females treated with DHT exhibited a 67\% increase in adipocyte cell size (Fig. 6D and $\mathrm{E} ; P<0.01$ ), adipocyte hypertrophy was not evident in testosterone-treated WT females or any of the ARKO groups (Fig. 6D and E). Additionally, we measured circulating levels of the adipocyte-derived hormone adiponectin, an adipokine reduced in serum of PCOS patients (Toulis et al. 2009, Baldani et al. 2019) and PCOS animal models (Yuan et al. 2016, Caldwell et al. 2017). Serum adiponectin concentrations were significantly reduced in DHT $(P<0.01)$ and testosterone $(P<0.05)$ exposed WT females (Fig. 7A), while no difference was observed between any of the ARKO treatment groups (Fig. 7A).

Cholesterol levels were increased in WT mice by DHT, but not testosterone, and neither androgen altered cholesterol levels in ARKO mice

To further assess the mechanism of androgen excess in mediating PCOS-like traits in this hyperandrogenic PCOSlike mouse model, serum cholesterol concentrations were measured, and DHT treatment was observed to induce a significant increase in levels in WT mice (Fig. 7B; $P<0.01$ ). In contrast, testosterone-treated WT mice and DHT- and 
A

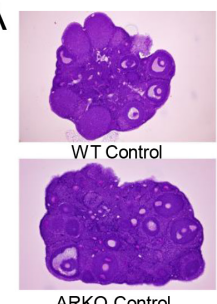

ARKO Control

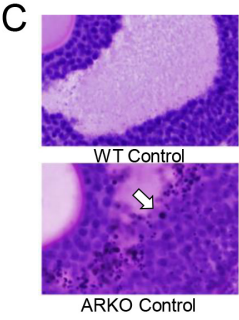

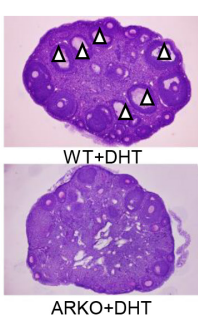

ARKO+DHT

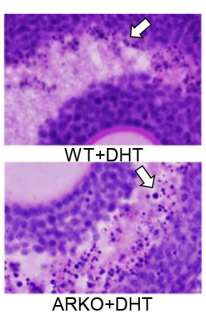

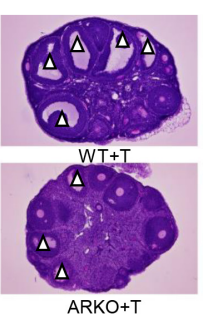

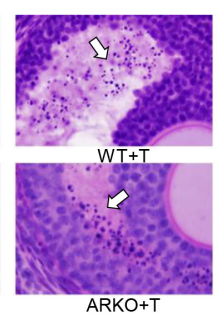

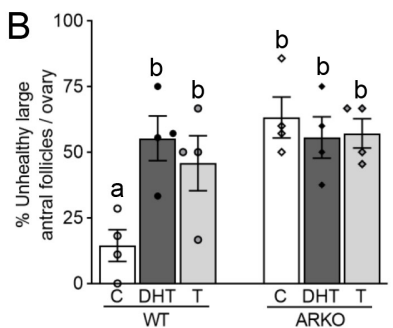

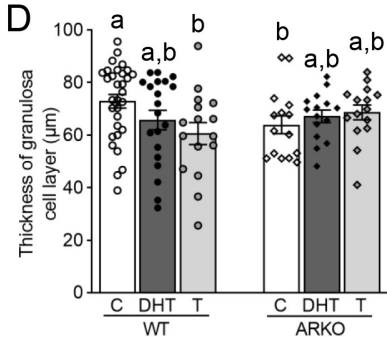

Figure 5

Both DHT and testosterone (T) induce the development of polycystic ovary morphology in WT mice, but only testosterone causes polycystic ovaries in ARKO mice. (A) Histological cross-sections of representative ovaries: showing the development of the classic PCOS ovarian phenotype, defined by the presence of multiple arrested large antral follicles, in DHT- and testosterone-induced PCOS WT mice and testosterone-induced PCOS ARKO female mice. Triangles: arrested large antral follicles; magnification 4×. (B) Proportion of unhealthy large antral follicles per ovary: showing a significant decrease in large antral follicles health in DHT and testosterone-treated WT mice. $n=4$ per treatment/genotype group. (C) Histological cross-section of representative antral follicles: showing presence of pyknotic cells (white arrows) within granulosa cell layer. Magnification: 40×. (D) Average thickness of granulosa cell layer per follicle: showing a significant reduction in granulosa cell-layer thickness in testosterone-induced PCOS WT mice. Average of 19 follicles assessed per treatment/genotype group. For all graphs, data are the mean \pm S.E.M.; different letters denote significant statistical differences; two-way ANOVA followed by Fishers's LSD post-hoc test.

testosterone-treated ARKO females displayed comparable cholesterol levels to control mice (Fig. 7B). Androgen excess caused no significant alteration in serum triglyceride levels (Fig. 7C). Compared with controls, testosteronetreated WT females had a significantly altered response 15 min and 30 min after glucose exposure and DHT-treated WT females displayed a similar but non-significant trend $(P=0.08) 15$ min after glucose exposure. No effect of androgen excess was observed in ARKO females (Fig. 7D) and overall glucose tolerance did not change in WT or ARKO mice (Fig. 7E).

\section{Discussion}

Although hyperandrogenism is a key defining feature of PCOS, the specific mechanism(s) through which androgens mediate the development of the PCOS phenotype remain unclear. The present study provides evidence to support the notion that androgens acting directly through the AR and indirectly, likely via the ER, both drive important mechanisms involved in mediating the development of reproductive dysfunction in PCOS. By contrast, only direct AR-mediated actions were observed to play a key role in establishing the PCOS-like metabolic traits (Table 1). Our data provide experimental evidence to support that the heterogeneity in the spectrum of PCOS symptoms observed may be due to difference in the underlying steroid signaling pathways involved.

We show that both testosterone and DHT were able to induce the reproductive PCOS traits of acyclicity, anovulation and polycystic ovarian morphology in WT mice, confirming the importance of androgen-driven mechanisms in PCOS pathogenesis (Walters et al. 2019). However, several androgens elevated in the serum of women with PCOS (testosterone, dehydroepiandrosterone (DHEA) and androstenedione $\left(\mathrm{A}_{4}\right)$ (Handelsman et al. 2017)) are aromatizable and can be further converted into corresponding estrogens which can mediate their effects via the ER (Hillier et al. 1994, Ghayee \& Auchus 2007). We show here that, while DHT-treated ARKO mice were protected against reproductive dysfunction, in the absence of a functional AR, reproductive features of PCOS can still be induced by excess exposure to testosterone. Testosterone-treated ARKO females exhibited irregular cycles, ovaries with a classic polycystic appearance and ovulatory dysfunction, which was confirmed by the reduction in CL numbers. AR activity is completely ablated globally in ARKO mice and while DHT can be converted into $3 \beta$-diol ( $5 \alpha$-androstane-3 $\beta, 17 \beta$-diol), which has the 


\begin{tabular}{l|l|l|r|r|}
$\begin{array}{l}\text { Journal of } \\
\text { Endocrinology }\end{array}$ & A Aflatounian et al. & $\begin{array}{l}\text { Mechanism of androgenic } \\
\text { actions in PCOS }\end{array}$ & $\mathbf{2 4 5 : 3}$ & $\mathbf{3 8 9}$ \\
\hline
\end{tabular}
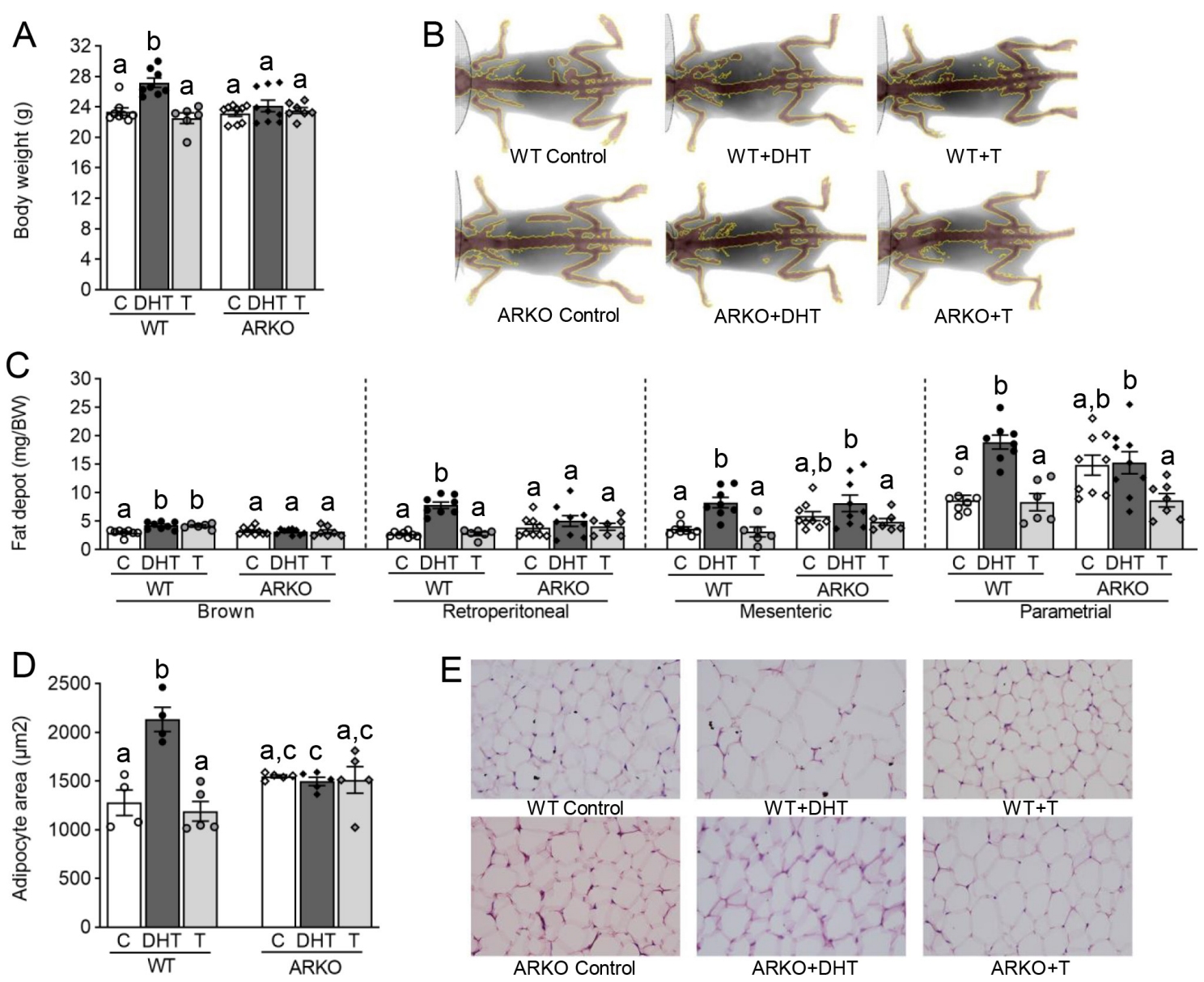

\section{Figure 6}

DHT, but not testosterone (T), increased body weight, adiposity and adipocyte hypertrophy in WT mice but neither androgen impacted body composition in ARKO mice. (A) Body weight: demonstrating increased body weight only in DHT- induced PCOS WT mice. $n=6-9$ per treatment/genotype group. (B) Representative dual-energy X-ray absorptiometry (DEXA) scan images: showing increased body fat in DHT-induced PCOS WT mice. (C) Brown, retroperitoneal, mesenteric and parametrial fat-pad weights: demonstrating an overall consistent significant increase in adiposity only in DHT-induced PCOS WT mice. (D) Parametrial adipocyte size: demonstrating that only DHT-induced PCOS WT mice displayed adipocyte hypertrophy. $n=4-5$ per treatment/genotype group. (E) Histological sections of representative parametrial adipose tissue from each treatment group: showing development of adipocyte hypertrophy in DHT-induced PCOS WT mice. Magnification: 40x. For all graphs data, are the mean \pm s.E.M.; different letters denote significant statistical differences; two-way ANOVA followed by Fishers's LSD post-hoc test.

potential to elicit ER $\beta$-mediated effects (Kuiper et al. 1997, Miller \& Auchus 2011), all ARKO females treated with DHT were protected against the development of reproductive features of PCOS. Taken together, the observed effects in the current study imply that androgen excess acting indirectly plays a role in mediating the development of reproductive dysfunction in PCOS, which we propose is primarily mediated via the ER. This proposal is consistent with current clinical recommendations that the firstline treatment options to induce ovulation in PCOS patients are the anti-estrogens letrozole and clomiphene (Kar 2012, Legro 2016, Teede et al. 2018), both of which modulate ER actions. Current evidence points to a key role for aberrant neuroendocrine actions in the origins of PCOS (Walters et al. 2018b), with AR signaling in the brain

(C) 2020 Society for Endocrinology Published by Bioscientifica Ltd.
Printed in Great Britain highlighted as a key mechanism involved (Caldwell et al. 2017, Silva et al. 2018). However, new data indicate that dysregulation of hypothalamic ER $\alpha$ signaling in ER $\alpha \mathrm{KO}$ mice caused irregular LH secretion and the development of a PCOS-like cystic ovarian phenotype (Arao et al. 2019). Hence, it may be speculated that neuroendocrine estrogen actions also play an important intermediate role in the androgen-mediated origins of reproductive traits of PCOS.

Women affected by obesity have a higher prevalence of PCOS, and women with PCOS have an increased risk of developing obesity and adverse metabolic traits (Lim et al. 2012, Moran et al. 2015). Hyperandrogenism and insulin resistance are both clinically present in women with PCOS and thought to play a role in PCOS pathogenesis, but the underlying mechanisms driving the development 

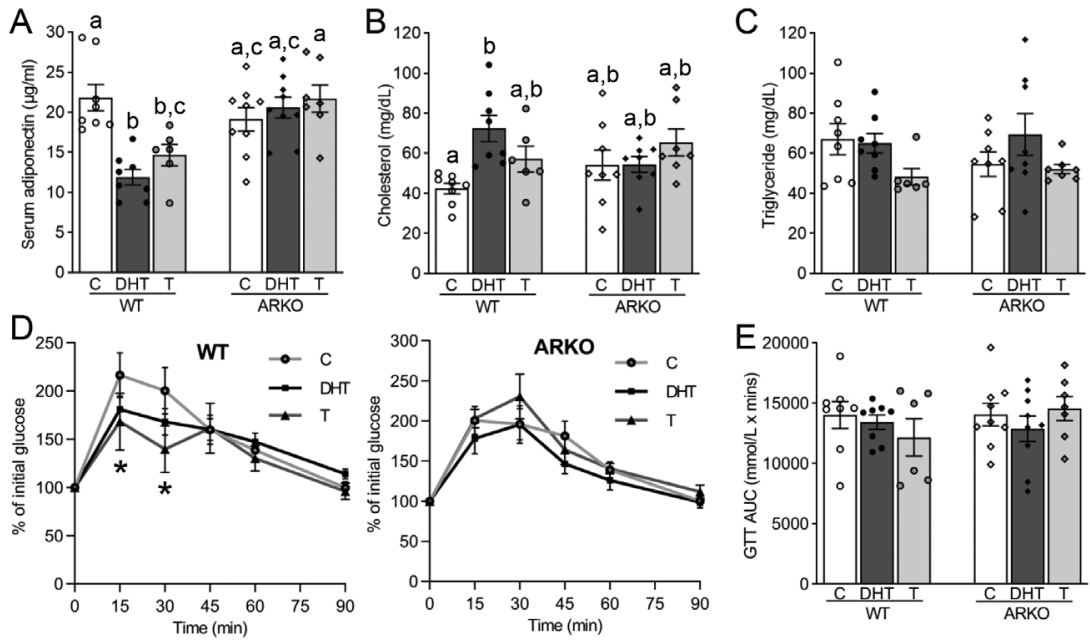

\section{Figure 7}

Circulating adiponectin and cholesterol levels are influenced by androgen excess in WT mice, but neither androgen altered serum levels in ARKO mice. (A) Serum adiponectin concentrations: showing DHT and testosterone (T) treatments in WT mice only induced decreased levels of adiponectin. (B) Serum cholesterol levels: demonstrating that only DHT-induced PCOS WT mice displayed elevated cholesterol levels. (C) Serum triglyceride levels: showing no elevation in triglyceride concentrations due to exposure to androgen excess. (D) Glucose tolerance test (GTT): glucose levels following intra-peritoneal injection of glucose, showing an altered response after glucose exposure in testosterone-treated PCOS WT mice only. (E) Area under the curve (AUC) analysis of the glucose tolerance test (GTT): showing no overall effect of androgen treatment. $n=6-9$ per treatment/genotype group. For all graphs, data are the mean \pm S.E.M.; different letters denote significant statistical differences; two-way ANOVA followed by Fishers's LSD post-hoc test (A, B, C and E) and repeated-measures two-way ANOVA followed by Fishers's LSD post-hoc test (D).

of adverse metabolic traits associated with PCOS remain to be fully elucidated. In the current study, we provide further support of a direct role for hyperandrogenism, acting directly via the $\mathrm{AR}$, in driving the high prevalence of obesity in women with PCOS. Treatment of WT females with non-aromatizable DHT induced a significant increase in body fat and fat-pad weights but, importantly, aromatizable testosterone had no effect in ARKO mice.

Table 1 Summary of the PCOS-like traits induced in WT and ARKO female mice after exposure to excess levels of an aromatizable (testosterone) and a non-aromatizable (DHT) androgen.

\begin{tabular}{l}
\hline \\
\hline Functional AR \\
Functional ER \\
Clinical PCOS trait \\
Reproductive features \\
$\quad$ Absent/irregular cycling \\
Oligo-anovulation \\
PCOM \\
Change in ovary weight a \\
$\uparrow$ Unhealthy large antral follicles \\
$\downarrow$ Granulosa cell-layer thickness \\
Metabolic features \\
$\uparrow$ Body weight \\
$\quad \uparrow$ Parametrial fat-pad weight \\
$\uparrow$ Retroperitoneal fat-pad weight \\
$\uparrow$ Mesenteric fat-pad weight \\
$\uparrow$ Brown fat-pad weight \\
$\quad$ Adipocyte hypertrophy \\
$\downarrow$ Serum adiponectin \\
$\uparrow$ Serum cholesterol \\
$\uparrow$ Serum triglyceride \\
Glucose intolerance
\end{tabular}

\begin{tabular}{ll}
\hline WT \\
\hline$\checkmark$ \\
$\checkmark$ \\
\\
\hline \\
$\checkmark$ \\
$\checkmark$ \\
$\checkmark$ \\
$\checkmark$ \\
$x$ \\
$\checkmark$ \\
$\checkmark$ \\
$\checkmark$ \\
$\checkmark$ \\
$\checkmark$ \\
$\checkmark$ \\
$\checkmark$ \\
$\checkmark$ \\
$x$ \\
$x$
\end{tabular}

\section{DHT}

ARKO
$\boldsymbol{x}$
$\boldsymbol{v}$

Development of PCOS-like trait?

\begin{tabular}{cc}
\hline \multicolumn{2}{c}{ Testosterone } \\
\hline WT & ARKO \\
& $X$ \\
$\checkmark$ & $\checkmark$
\end{tabular}

\section{$x$}
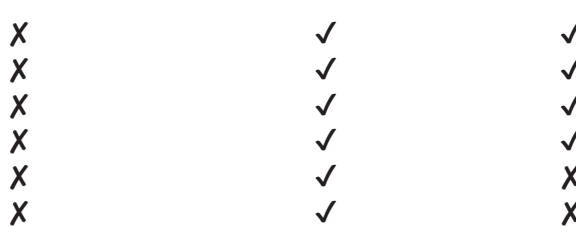

$\checkmark$, clinical PCOS trait present; $\boldsymbol{X}$, clinical PCOS trait not present; a, $\uparrow$ in humans; $\downarrow$, in mice. https://joe.bioscientifica.com https://doi.org/10.1530/JOE-19-0530
(C) 2020 Society for Endocrinology Published by Bioscientifica Ltd. Printed in Great Britain 
These findings infer that androgen excess acting via AR, and not ER, signaling was important in the establishment of the PCOS-like metabolic trait of increased adiposity. Androgen excess is known to induce metabolic features of PCOS in several animal models (Abbott et al. 2013, Padmanabhan \& Veiga-Lopez 2013, Walters et al. 2019) and a global loss of AR signaling fully protects female mice from the development of PCOS metabolic traits (Caldwell et al. 2017), inferring direct androgen signaling through the AR is key in the development of adverse metabolic traits. Clinical evidence supporting this comes from the findings that treatment of PCOS patients with the AR blocker flutamide improved lipid profile independent of changes in weight (Diamanti-Kandarakis et al. 1998), and in combination with a hypocaloric diet in overweightobese PCOS women, flutamide had a beneficial effect on glucose-stimulated glucose levels, insulin sensitivity and low-density lipoprotein and cholesterol levels (Gambineri et al. 2006). Moreover, mechanistic support of a role for AR comes from a study using a PCOS-prone metabolic syndrome rodent model (generated without androgen excess treatments), where it was shown that flutamide improved the dyslipidemia observed in this model (Kupreeva et al. 2019).

Several clinical studies demonstrate a positive correlation between circulating androgen concentrations and the prevalence of adverse metabolic traits in patients with PCOS (Christakou \& Diamanti-Kandarakis 2008, O'Reilly et al. 2014, Zhang et al. 2018). However, in the current study, testosterone was not able to induce the adverse metabolic traits observed in the DHT-treated WT females. One reason for this could be that the testosterone dose used was not potent enough to induce metabolic traits, or another possibility is that testosterone was being aromatized into estradiol opposing some androgen actions, further indicating that ER signaling is not crucial in the development of PCOS metabolic traits. This lack of effect of testosterone differs from hyperandrogenic PCOS women who have an adverse metabolic phenotype (reduced insulin sensitivity and dysglycemia) which is associated with increased testosterone and androstenedione (A4) serum levels (O'Reilly et al. 2014). This may reflect that women with PCOS may display reduced aromatization of testosterone to E2, an interpretation supported by finding that PCOS patients exhibit significantly lower E2/testosterone ratios (Chen et al. 2015) and consistent with the reported reduced expression of CYP19A1 in ovaries from PCOS patients (Yu et al. 2013). A key role for direct androgen signaling via $\mathrm{AR}$, and not via $\mathrm{ER}$, in the establishment of adverse metabolic traits was further supported by the findings that, in WT mice, DHT, but not testosterone, also induced the PCOS-like metabolic features of adipocyte hypertrophy, a decrease in serum adiponectin levels and an increase in circulating cholesterol levels. Consistent with these findings, hyperandrogenized rodent, sheep and primate PCOS models all display altered adipocyte morphology (Keller et al. 2014, Cardoso et al. 2016, Caldwell et al. 2017) and intra-abdominal fat mass is significantly increased in women with PCOS, and this increase is positively correlated with serum androgen levels and fasting insulin levels (Dumesic et al. 2016). In addition, females rats exposed to elevated levels of estradiol valerate exhibit several reproductive PCOS-like traits (Brawer et al. 1986, McCarthy \& Brawer 1990), but lack metabolic features associated with human PCOS (Stener-Victorin et al. 2000).

PCOS patients can be divided into four phenotypes (A-D) based on the presence of the Rotterdam diagnostic criteria (Lizneva et al. 2016). Interestingly, nonhyperandrogenic PCOS patients (phenotype D) are reported to display a lower risk of developing metabolic PCOS traits than the other three hyperandrogenic PCOS phenotypes (Zhang et al. 2009, Kar 2013, Clark et al. 2014, Altintas et al. 2017, Tripathy et al. 2018). Therefore, this raises the question of whether non-hyperandrogenic PCOS patients are etiologically distinct from women with PCOS who display hyperandrogenism (Azziz et al. 2006, 2009). In our current study, direct AR-mediated androgen actions were required for the manifestation of metabolic PCOS-like features in WT mice. This suggests that, in PCOS phenotypes displaying hyperandrogenism, AR- but not ER-mediated actions are primarily responsible for the higher prevalence of metabolic traits in these patients and supports treatments based on AR antagonism. There is also a striking similarity between the PCOS characteristics displayed in non-hyperandrogenic PCOS patients and those we propose are induced via ER-mediated action in our mice, as both of these groups exhibit disrupted ovulation and polycystic ovarian morphology. Based on our data, we hypothesize that, ER, and not AR, signaling may be the key mediator in the development of the reproductive abnormalities observed in PCOS women with phenotype $\mathrm{D}$, and treatments that modulate $\mathrm{ER}$ actions may be more beneficial, hence this area warrants further research.

While species differences need to be considered when interpreting rodent models of PCOS, carefully designed experiments using animal models that display characteristics of the human condition of PCOS with 
Exposure to androgen excess

Proposed signaling mechanisms mediating the development of PCOS traits
PCOS traits developed in adulthood
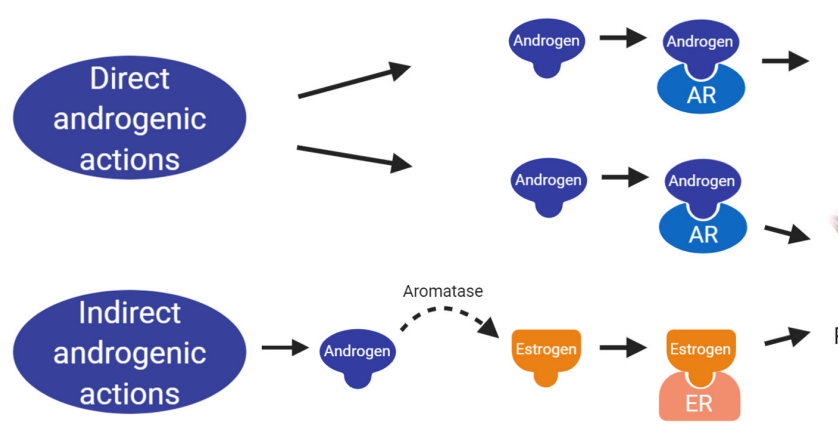

high fidelity are valuable tools as they afford insights into fundamental biological mechanisms impacting on the development of PCOS, noting that reproductive functions are highly conserved in mammals. This study used a rodent model of PCOS to provide insight into the androgen signaling pathways involved in the genesis of both reproductive and metabolic abnormalities that are characteristic of many women with PCOS. We have provided evidence to support that hyperandrogenism acting directly via the $\mathrm{AR}$, and likely also indirectly via the ER, can induce key PCOS-like reproductive traits in a preclinical PCOS mouse model. We also highlight the important role for AR-mediated androgen actions, and lack of evidence for estrogenic actions, in the pathogenesis of adverse metabolic traits associated with experimental PCOS. Future studies which incorporate ER antagonists and which undertake a detailed characterisation of intracrine steroid biosynthesis in PCOS animal models could further define the precise underlying mechanisms and pathways involved. Overall, these data provide evidence to put forward a hypothesis that the manifestation of the different clinical PCOS subphenotypes arise through variations in the underlying signaling pathways involved, with both direct and indirect androgen signaling pathways playing key and divergent roles (Fig. 8). The clinical implications of these findings are that potentially different PCOS phenotypes may have distinct pathogenesis and prognosis, which require a phenotype-driven therapeutic approach to ensure the underlying mechanisms are effectively targeted.

\section{Declaration of interest}

The authors declare that there is no conflict of interest that could be perceived as prejudicing the impartiality of the research reported.

\section{Funding}

This study was supported by National Health and Medical Research Council project grant (APP1022648), Project Support Funding from the ANZAC Research Institute and by the School of Women's and Children's Health, University of New South Wales Sydney, including a PhD Scholarship awarded to Ali Aflatounian.

\section{Author contribution statement}

$A$ A, D J H and K A W Walters designed research. A A, M C E, V R P and R D conducted research and acquired data. A A, RB G, D J H and K A W analyzed and interpreted data. A A, M C E, M J B, R D, W L L, R B G, D J H and K A W wrote, reviewed and revised the manuscript.

\section{Acknowledgements}

The authors thank Jenny Spaliviero, Manjula Magamage, Mamdouh Khalil and the staff of the ANZAC animal facility for experimental support. Figure 8 was created with BioRender.com.

\section{References}

Abbott DH, Nicol LE, Levine JE, Xu N, Goodarzi MO \& Dumesic DA 2013 Nonhuman primate models of polycystic ovary syndrome. Molecular and Cellular Endocrinology 373 21-28. (https://doi.org/10.1016/j. mce.2013.01.013)

Abi Salloum B, Veiga-Lopez A, Abbott DH, Burant CF \& Padmanabhan V 2015 Developmental programming: exposure to testosterone excess disrupts steroidal and metabolic environment in pregnant sheep. Endocrinology 156 2323-2337. (https://doi.org/10.1210/en.2014-2006)

Altintas KZ, Dilbaz B, Cirik DA, Ozelci R, Zengin T, Erginay ON \& Dilbaz S 2017 The incidence of metabolic syndrome in adolescents with different phenotypes of PCOS. Ginekologia Polska 88 289-295. (https://doi.org/10.5603/GP.a2017.0055)

Arao Y, Hamilton KJ, Wu SP, Tsai MJ, Demayo FJ \& Korach KS 2019 Dysregulation of hypothalamic-pituitary estrogen receptor alpha-mediated signaling causes episodic LH secretion and cystic ovary. FASEB Journal 33 7375-7386. (https://doi.org/10.1096/ fj.201802653RR)

Armstrong DT, Moon YS \& Leung PC 1976 Uterotrophic effects of testosterone and 5alpha-dihydrotestosterone in intact and https://joe.bioscientifica.com https://doi.org/10.1530/JOE-19-0530
(C) 2020 Society for Endocrinology Published by Bioscientifica Ltd. Printed in Great Britain 
ovariectomized immature female rats. Biology of Reproduction 15 107-114. (https://doi.org/10.1095/biolreprod15.1.107)

Azziz R, Carmina E, Dewailly D, Diamanti-Kandarakis E, EscobarMorreale HF, Futterweit W, Janssen OE, Legro RS, Norman RJ, Taylor AE, et al. 2006 Positions statement: Criteria for defining polycystic ovary syndrome as a predominantly hyperandrogenic syndrome: an androgen excess society guideline. Journal of Clinical Endocrinology and Metabolism 91 4237-4245. (https://doi.org/10.1210/ jc.2006-0178)

Azziz R, Carmina E, Dewailly D, Diamanti-Kandarakis E, EscobarMorreale HF, Futterweit W, Janssen OE, Legro RS, Norman RJ, Taylor AE, et al. 2009 The androgen excess and PCOS Society criteria for the polycystic ovary syndrome: the complete task force report. Fertility and Sterility 91 456-488. (https://doi.org/10.1016/j. fertnstert.2008.06.035)

Baldani DP, Skrgatic L, Kasum M, Zlopasa G, Kralik Oguic S \& Herman M 2019 Altered leptin, adiponectin, resistin and ghrelin secretion may represent an intrinsic polycystic ovary syndrome abnormality. Gynecological Endocrinology 35 401-405. (https://doi.org/10.1080/0951 3590.2018.1534096)

Brawer JR, Munoz M \& Farookhi R 1986 Development of the polycystic ovarian condition (PCO) in the estradiol valerate-treated rat. Biology of Reproduction 35 647-655. (https://doi.org/10.1095/ biolreprod35.3.647)

Caldwell AS, Middleton LJ, Jimenez M, Desai R, Mcmahon AC, Allan CM, Handelsman DJ \& Walters KA 2014 Characterization of reproductive, metabolic, and endocrine features of polycystic ovary syndrome in female hyperandrogenic mouse models. Endocrinology 155 3146-3159. (https://doi.org/10.1210/en.2014-1196)

Caldwell AS, Eid S, Kay CR, Jimenez M, Mcmahon AC, Desai R, Allan CM, Smith JT, Handelsman DJ \& Walters KA 2015 Haplosufficient genomic androgen receptor signaling is adequate to protect female mice from induction of polycystic ovary syndrome features by prenatal hyperandrogenization. Endocrinology 156 1441-1452. (https://doi. org/10.1210/en.2014-1887)

Caldwell ASL, Edwards MC, Desai R, Jimenez M, Gilchrist RB, Handelsman DJ \& Walters KA 2017 Neuroendocrine androgen action is a key extraovarian mediator in the development of polycystic ovary syndrome. PNAS 114 E3334-E3343. (https://doi.org/10.1073/ pnas.1616467114)

Cardoso RC, Veiga-Lopez A, Moeller J, Beckett E, Pease A, Keller E, Madrigal V, Chazenbalk G, Dumesic D \& Padmanabhan V 2016 Developmental programming: impact of gestational steroid and metabolic milieus on adiposity and insulin sensitivity in prenatal testosterone-treated female sheep. Endocrinology 157 522-535. (https://doi.org/10.1210/en.2015-1565)

Chen J, Shen S, Tan Y, Xia D, Xia Y, Cao Y, Wang W, Wu X, Wang H, Yi L, et al. 2015 The correlation of aromatase activity and obesity in women with or without polycystic ovary syndrome. Journal of Ovarian Research 8 11. (https://doi.org/10.1186/s13048-015-0139-1)

Cheng XB, Jimenez M, Desai R, Middleton LJ, Joseph SR, Ning G, Allan CM, Smith JT, Handelsman DJ \& Walters KA 2013 Characterizing the neuroendocrine and ovarian defects of androgen receptor-knockout female mice. American Journal of Physiology: Endocrinology and Metabolism 305 E717-E726. (https://doi. org/10.1152/ajpendo.00263.2013)

Christakou CD \& Diamanti-Kandarakis E 2008 Role of androgen excess on metabolic aberrations and cardiovascular risk in women with polycystic ovary syndrome. Women's Health 4 583-594. (https://doi. org/10.2217/17455057.4.6.583)

Clark NM, Podolski AJ, Brooks ED, Chizen DR, Pierson RA, Lehotay DC \& Lujan ME 2014 Prevalence of polycystic ovary syndrome phenotypes using updated criteria for polycystic ovarian morphology: an assessment of over 100 consecutive women self-reporting features of polycystic ovary syndrome. Reproductive Sciences 21 1034-1043. (https://doi.org/10.1177/1933719114522525)
Davison SL \& Davis SR 2003 Androgens in women. Journal of Steroid Biochemistry and Molecular Biology 85 363-366. (https://doi. org/10.1016/s0960-0760(03)00204-8)

Desai R, Harwood DT \& Handelsman DJ 2019 Simultaneous measurement of 18 steroids in human and mouse serum by liquid chromatography-mass spectrometry without derivatization to profile the classical and alternate pathways of androgen synthesis and metabolism. Clinical Mass Spectrometry 11 42-51. (https://doi. org/10.1016/j.clinms.2018.12.003)

Diamanti-Kandarakis E, Mitrakou A, Raptis S, Tolis G \& Duleba AJ 1998 The effect of a pure antiandrogen receptor blocker, flutamide, on the lipid profile in the polycystic ovary syndrome. Journal of Clinical Endocrinology and Metabolism 83 2699-2705. (https://doi.org/10.1210/ jcem.83.8.5041)

Dumesic DA, Oberfield SE, Stener-Victorin E, Marshall JC, Laven JS \& Legro RS 2015 Scientific statement on the diagnostic criteria, epidemiology, pathophysiology, and molecular genetics of polycystic ovary syndrome. Endocrine Reviews 36 487-525. (https://doi. org/10.1210/er.2015-1018)

Dumesic DA, Akopians AL, Madrigal VK, Ramirez E, Margolis DJ, Sarma MK, Thomas AM, Grogan TR, Haykal R, Schooler TA, et al. 2016 Hyperandrogenism accompanies increased intra-abdominal fat storage in normal weight polycystic ovary syndrome women. Journal of Clinical Endocrinology and Metabolism 101 4178-4188. (https://doi. org/10.1210/jc.2016-2586)

Gambineri A, Patton L, Vaccina A, Cacciari M, Morselli-Labate AM, Cavazza C, Pagotto U \& Pasquali R 2006 Treatment with flutamide, metformin, and their combination added to a hypocaloric diet in overweight-obese women with polycystic ovary syndrome: a randomized, 12-month, placebo-controlled study. Journal of Clinical Endocrinology and Metabolism 91 3970-3980. (https://doi.org/10.1210/ jc.2005-2250)

Ghayee HK \& Auchus RJ 2007 Basic concepts and recent developments in human steroid hormone biosynthesis. Reviews in Endocrine and Metabolic Disorders 8 289-300. (https://doi.org/10.1007/s11154-007-9052-2)

Gilling-Smith C, Willis DS, Beard RW \& Franks S 1994 Hypersecretion of androstenedione by isolated thecal cells from polycystic ovaries. Journal of Clinical Endocrinology and Metabolism 79 1158-1165. (https://doi.org/10.1210/jcem.79.4.7962289)

Glintborg D, Rubin KH, Nybo M, Abrahamsen B \& Andersen M 2018 Cardiovascular disease in a nationwide population of Danish women with polycystic ovary syndrome. Cardiovascular Diabetology 1737. (https://doi.org/10.1186/s12933-018-0680-5)

Handelsman DJ, Teede HJ, Desai R, Norman RJ \& Moran LJ 2017 Performance of mass spectrometry steroid profiling for diagnosis of polycystic ovary syndrome. Human Reproduction 32 418-422. (https:// doi.org/10.1093/humrep/dew328)

Hillier SG, Whitelaw PF \& Smyth CD 1994 Follicular oestrogen synthesis: the 'two-cell, two-gonadotrophin' model revisited. Molecular and Cellular Endocrinology 100 51-54. (https://doi.org/10.1016/03037207(94)90278-x)

Kar S 2012 Clomiphene citrate or letrozole as first-line ovulation induction drug in infertile PCOS women: a prospective randomized trial. Journal of Human Reproductive Sciences 5 262-265. (https://doi. org/10.4103/0974-1208.106338)

Kar S 2013 Anthropometric, clinical, and metabolic comparisons of the four Rotterdam PCOS phenotypes: a prospective study of PCOS women. Journal of Human Reproductive Sciences 6 194-200. (https://doi. org/10.4103/0974-1208.121422)

Keller E, Chazenbalk GD, Aguilera P, Madrigal V, Grogan T, Elashoff D, Dumesic DA \& Abbott DH 2014 Impaired preadipocyte differentiation into adipocytes in subcutaneous abdominal adipose of PCOS-like female rhesus monkeys. Endocrinology 155 2696-2703. (https://doi. org/10.1210/en.2014-1050)

Kuiper GG, Carlsson B, Grandien K, Enmark E, Haggblad J, Nilsson S \& Gustafsson JA 1997 Comparison of the ligand binding specificity https://joe.bioscientifica.com

https://doi.org/10.1530/JOE-19-0530 (c) 2020 Society for Endocrinology Published by Bioscientifica Ltd. Printed in Great Britain 
and transcript tissue distribution of estrogen receptors alpha and beta. Endocrinology 138 863-870. (https://doi.org/10.1210/ endo.138.3.4979)

Kupreeva M, Diane A, Lehner R, Watts R, Ghosh M, Proctor S \& Vine D 2019 Effect of metformin and flutamide on insulin, lipogenic and androgen-estrogen signaling, and cardiometabolic risk in a PCOSprone metabolic syndrome rodent model. American Journal of Physiology: Endocrinology and Metabolism 316 E16-E33. (https://doi. org/10.1152/ajpendo.00018.2018)

Legro RS 2016 Ovulation induction in polycystic ovary syndrome: current options. Best Practice and Research: Clinical Obstetrics and Gynaecology 37 152-159. (https://doi.org/10.1016/j. bpobgyn.2016.08.001)

Lim SS, Davies MJ, Norman RJ \& Moran LJ 2012 Overweight, obesity and central obesity in women with polycystic ovary syndrome: a systematic review and meta-analysis. Human Reproduction Update $\mathbf{1 8}$ 618-637. (https://doi.org/10.1093/humupd/dms030)

Livadas S, Pappas C, Karachalios A, Marinakis E, Tolia N, Drakou M, Kaldrymides P, Panidis D \& Diamanti-Kandarakis E 2014 Prevalence and impact of hyperandrogenemia in 1,218 women with polycystic ovary syndrome. Endocrine 47 631-638. (https://doi.org/10.1007/ s12020-014-0200-7)

Lizneva D, Suturina L, Walker W, Brakta S, Gavrilova-Jordan L \& Azziz R 2016 Criteria, prevalence, and phenotypes of polycystic ovary syndrome. Fertility and Sterility 106 6-15. (https://doi.org/10.1016/j. fertnstert.2016.05.003)

Lucis OJ, Hobkirk R, Hollenberg CH, Macdonald SA \& Blahey P 1966 Polycystic ovaries associated with congenital adrenal hyperplasia. Canadian Medical Association Journal 94 1-7.

March WA, Moore VM, Willson KJ, Phillips DI, Norman RJ \& Davies MJ 2010 The prevalence of polycystic ovary syndrome in a community sample assessed under contrasting diagnostic criteria. Human Reproduction 25 544-551. (https://doi.org/10.1093/humrep/dep399)

Mccarthy GF \& Brawer JR 1990 Induction of Stein-Leventhal-like polycystic ovaries (PCO) in the rat: a new model for cystic ovarian disease. Anatomical Record 228 137-144. (https://doi.org/10.1002/ ar.1092280205)

Mcnamara KM, Harwood DT, Simanainen U, Walters KA, Jimenez M \& Handelsman DJ 2010 Measurement of sex steroids in murine blood and reproductive tissues by liquid chromatography-tandem mass spectrometry. Journal of Steroid Biochemistry and Molecular Biology 121 611-618. (https://doi.org/10.1016/j.jsbmb.2010.02.001)

Miller WL \& Auchus RJ 2011 The molecular biology, biochemistry, and physiology of human steroidogenesis and its disorders. Endocrine Reviews 32 81-151. (https://doi.org/10.1210/er.2010-0013)

Moran LJ, Norman RJ \& Teede HJ 2015 Metabolic risk in PCOS: phenotype and adiposity impact. Trends in Endocrinology and Metabolism 26 136-143. (https://doi.org/10.1016/j.tem.2014.12.003)

O'Reilly MW, Taylor AE, Crabtree NJ, Hughes BA, Capper F, Crowley RK, Stewart PM, Tomlinson JW \& Arlt W 2014 Hyperandrogenemia predicts metabolic phenotype in polycystic ovary syndrome: the utility of serum androstenedione. Journal of Clinical Endocrinology and Metabolism 99 1027-1036. (https://doi.org/10.1210/jc.20133399)

Pache TD \& Fauser BC 1993 Polycystic ovaries in female-to-male transsexuals. Clinical Endocrinology 39 702-703.

Padmanabhan V \& Veiga-Lopez A 2013 Sheep models of polycystic ovary syndrome phenotype. Molecular and Cellular Endocrinology 373 8-20. (https://doi.org/10.1016/j.mce.2012.10.005)

Paradisi R, Fabbri R, Battaglia C \& Venturoli S 2013 Ovulatory effects of flutamide in the polycystic ovary syndrome. Gynecological Endocrinology 29 391-395. (https://doi.org/10.3109/09513590.2012. 754876)

Rotterdam ESHRE/ASRM-Sponsored PCOS Consensus Workshop Group 2004 Revised 2003 consensus on diagnostic criteria and long-term health risks related to polycystic ovary syndrome (PCOS). Human Reproduction 19 41-47. (https://doi.org/10.1093/humrep/deh098)

Rubin KH, Glintborg D, Nybo M, Abrahamsen B \& Andersen M 2017 Development and risk factors of Type 2 diabetes in a nationwide population of women with polycystic ovary syndrome. Journal of Clinical Endocrinology and Metabolism 102 3848-3857. (https://doi. org/10.1210/jc.2017-01354)

Ryan GE, Malik S \& Mellon PL 2018 Antiandrogen treatment ameliorates reproductive and metabolic phenotypes in the letrozole-induced mouse model of PCOS. Endocrinology 159 1734-1747. (https://doi. org/10.1210/en.2017-03218)

Shorakae S, Boyle J \& Teede H 2014 Polycystic ovary syndrome: a common hormonal condition with major metabolic sequelae that physicians should know about. Internal Medicine Journal 44 720-726. (https://doi.org/10.1111/imj.12495)

Shukla A, Shukla GS \& Radin NS 1992 Control of kidney size by sex hormones: possible involvement of glucosylceramide. American Journal of Physiology 262 F24-F29. (https://doi.org/10.1152/ ajprenal.1992.262.1.F24)

Silva MS, Prescott M \& Campbell RE 2018 Ontogeny and reversal of brain circuit abnormalities in a preclinical model of PCOS. JCI Insight 3 99405. (https://doi.org/10.1172/jci.insight.99405)

Singh J, O'neill C \& Handelsman DJ 1995 Induction of spermatogenesis by androgens in gonadotropin-deficient (hpg) mice. Endocrinology 136 5311-5321. (https://doi.org/10.1210/endo.136.12.7588276)

Smith P, Steckler TL, Veiga-Lopez A \& Padmanabhan V 2009 Developmental programming: differential effects of prenatal testosterone and dihydrotestosterone on follicular recruitment, depletion of follicular reserve, and ovarian morphology in sheep. Biology of Reproduction 80 726-736. (https://doi.org/10.1095/ biolreprod.108.072801)

Stener-Victorin E, Lundeberg T, Waldenstrom U, Manni L, Aloe L, Gunnarsson S \& Janson PO 2000 Effects of electro-acupuncture on nerve growth factor and ovarian morphology in rats with experimentally induced polycystic ovaries. Biology of Reproduction 63 1497-1503. (https://doi.org/10.1095/biolreprod63.5.1497)

Teede HJ, Misso ML, Costello MF, Dokras A, Laven J, Moran L, Piltonen T, Norman RJ \& International PCOS Network 2018 Recommendations from the international evidence-based guideline for the assessment and management of polycystic ovary syndrome. Human Reproduction 33 1602-1618. (https://doi.org/10.1093/humrep/dey256)

Toulis KA, Goulis DG, Farmakiotis D, Georgopoulos NA, Katsikis I, Tarlatzis BC, Papadimas I \& Panidis D 2009 Adiponectin levels in women with polycystic ovary syndrome: a systematic review and a meta-analysis. Human Reproduction Update 15 297-307. (https://doi. org/10.1093/humupd/dmp006)

Tripathy P, Sahu A, Sahu M \& Nagy A 2018 Metabolic risk assessment of Indian women with polycystic ovarian syndrome in relation to four Rotterdam criteria based phenotypes. European Journal of Obstetrics, Gynecology, and Reproductive Biology 224 60-65. (https://doi. org/10.1016/j.ejogrb.2018.02.031)

Veiga-Lopez A, Steckler TL, Abbott DH, Welch KB, Mohankumar PS, Phillips DJ, Refsal K \& Padmanabhan V 2011 Developmental programming: impact of excess prenatal testosterone on intrauterine fetal endocrine milieu and growth in sheep. Biology of Reproduction $\mathbf{8 4}$ 87-96. (https://doi.org/10.1095/biolreprod.110.086686)

Walters KA 2015 Role of androgens in normal and pathological ovarian function. Reproduction 149 R193-R218. (https://doi.org/10.1530/REP14-0517)

Walters KA, Allan CM, Jimenez M, Lim PR, Davey RA, Zajac JD, Illingworth P \& Handelsman DJ 2007 Female mice haploinsufficient for an inactivated androgen receptor (AR) exhibit age-dependent defects that resemble the AR null phenotype of dysfunctional late follicle development, ovulation, and fertility. Endocrinology 148 3674-3684. (https://doi.org/10.1210/en.2007-0248) https://joe.bioscientifica.com https://doi.org/10.1530/JOE-19-0530 (c) 2020 Society for Endocrinology Published by Bioscientifica Ltd. Printed in Great Britain 
Walters KA, Bertoldo MJ \& Handelsman DJ 2018a Evidence from animal models on the pathogenesis of PCOS. Best Practice and Research: Clinical Endocrinology and Metabolism 32 271-281. (https://doi. org/10.1016/j.beem.2018.03.008)

Walters KA, Gilchrist RB, Ledger WL, Teede HJ, Handelsman DJ \& Campbell RE $2018 b$ New perspectives on the pathogenesis of PCOS: neuroendocrine origins. Trends in Endocrinology and Metabolism 29 841-852. (https://doi.org/10.1016/j.tem.2018.08.005)

Walters KA, Rodriguez Paris V, Aflatounian A \& Handelsman DJ 2019 Androgens and ovarian function: translation from basic discovery research to clinical impact. Journal of Endocrinology 242 R23-R50. (https://doi.org/10.1530/JOE-19-0096)

Wang R, Li W, Bordewijk EM, Legro RS, Zhang H, Wu X, Gao J, MorinPapunen L, Homburg R, Konig TE, et al. 2019 First-line ovulation induction for polycystic ovary syndrome: an individual participant data meta-analysis. Human Reproduction Update 25 717-732. (https:// doi.org/10.1093/humupd/dmz029)

Yu YY, Sun CX, Liu YK, Li Y, Wang L \& Zhang W 2013 Promoter methylation of CYP19A1 gene in Chinese polycystic ovary syndrome patients. Gynecologic and Obstetric Investigation 76 209-213. (https:// doi.org/10.1159/000355314)

Yuan X, Hu T, Zhao H, Huang Y, Ye R, Lin J, Zhang C, Zhang H, Wei G, Zhou H, et al. 2016 Brown adipose tissue transplantation ameliorates polycystic ovary syndrome. PNAS 113 2708-2713. (https://doi. org/10.1073/pnas.1523236113)

Zawadzki J \& Dunaif A 1992 Diagnostic criteria for polycystic syndrome: towards a rational approach. In Polycystic Ovary Syndrome, pp. 337-384. Eds A Dunaif, JR Givens, FP Haseltine, \& GR Merriam. Boston, MA. USA: Blackwell Scientific Publications.

Zhang HY, Zhu FF, Xiong J, Shi XB \& Fu SX 2009 Characteristics of different phenotypes of polycystic ovary syndrome based on the Rotterdam criteria in a large-scale Chinese population. BJOG 116 1633-1639. (https://doi.org/10.1111/j.1471-0528.2009.02347.x)

Zhang B, Wang J, Shen S, Liu J, Sun J, Gu T, Ye X, Zhu D \& Bi Y 2018 Association of androgen excess with glucose intolerance in women with polycystic ovary syndrome. BioMed Research International 2018 6869705. (https://doi. org/10.1155/2018/6869705)

Received in final form 23 March 2020

Accepted 25 March 2020

Accepted Manuscript published online 31 March 2020
(C) 2020 Society for Endocrinology Published by Bioscientifica Ltd. 